\title{
¿Por qué leer la prensa regional hoy en día?
}

Loïc Ballarini

CEMTI (Centre d'études sur les médias, les technologies et l'internationalisation)

Université Paris 8, France

\section{Palabras clave}

Prensa regional, espacio público, conversación, estudios de recepción

\section{Resumen}

A pesar de un declive continuo en sus ventas, la prensa diaria y semanal regional permanece en Francia como el tipo de prensa de información más leída, muy por delante de los diarios nacionales y las revistas de información. Este artículo busca comprender por qué se lee hoy en día la prensa local. Extraído de mi tesis, los resultados surgieron de entrevistas con los lectores así como de un análisis de contenido de la prensa regional bretona. Las motivaciones para leer periódicos regionales permanecen estables en el tiempo. Para empezar, uno no elije su «periódico preferido»: frecuentemente, se hereda la lectura de los padres, o bien, se lee lo que está disponible en el lugar donde se come. Existen, a continuación, dos maneras de leer un regional. Una lectura geográfica que reenvía a las diferentes escalas del territorio y una lectura temática, que descansa sobre los centros de interés (información-servicios, resultados deportivos, obituarios...). Tanto en un caso como en el otro, la prensa regional aparece lejos de la misión de animadora del espacio público local que reivindica. No participa menos en el mantenimiento de un entramado social elemental que pasa por la transmisión de informaciones prácticas y noticias detalladas. La prensa regional no puede considerarse como la única representante del espacio público, pero constituye un elemento de la misma. Desde el punto de vista del lector, es un complemento de otros medios de comunicación, notablemente los digitales y las conversaciones cotidianas. Esta constatación es una invitación a redefinir el espacio público de una manera más abierta, fragmentada y dinámica. Esto puede alcanzarse abriendo la concepción del espacio público a nuevas dimensiones, tales como los intercambios orales diarios (Arendt), la articulación entre las escalas de territorio (Lacoste) y los procesos de socialización (Elias, Percherón), donde lo local es el lugar privilegiado. 


\title{
Why read the regional press today?
}

\section{Keywords}

Regional press, public sphere, ronversation, reception studies

\begin{abstract}
Although its audience continues to decline, the regional press sells more copies than national newspapers and newsmagazines and remains the reference for printed information in France. This article examines why one would read the regional press today by analysing interviews with readers. It is taken from my thesis and was preceded by a content analysis of the french regional press. The reading motivations appear to be stable over time. One does not choose his "favorite newspaper". Most of the times a reader inherits a reading habit from his family, otherwise he reads what is available where he is used to lunch. It then exists two ways of reading the regional press: a geographical one, which is focused on the different scales of territory, and a thematical one, which relies on centers of interest (sport, classified ads, obituaries...). In both ways, the regional press is far from what it claims to be its mission, i.e. facilitating the public sphere, but it helps maintain social links by transmitting practical information and local news. It can not be considered as the public sphere itself, but remains an element of it. On the readers' point of view, it appears to be complementary to other media, particularly digital, and to everyday conversations. This observation is an invitation to redefine the local public sphere in a more open, fragmented and dynamic way. It can be achieved by opening the concept of public sphere to new dimensions such as oral interactions (Arendt), cross-analysis of territory scales (Lacoste), and socialization processes (Elias, Percheron).
\end{abstract}

\begin{abstract}
Autor
Loïc Ballarini [loic.ballarini@free.fr]es profesor investigador en la Universidad de Galatasaray (Estambul) y miembro del CEMTI (Centro de estudios sobre los medios de comunicación, las tecnologías y la internacionalización) de la Universidad Paris 8, en Francia. Sus investigaciones versan sobre el espacio público y la prensa regional.
\end{abstract}




\section{Introducción}

«8/10. Gracias a los 8 costarmoricanos de cada 10 que nos leen» Así decía el eslogan de la campaña publicitaria lanzada por Ouest France en las Costas de Armor durante el invierno 2010-2011. Se podría discutir, evidentemente, la manera en que se estableció este anuncio ${ }^{1}$. Igualmente, se podría interpretar su presentación de diversas maneras: 8/10, es una puntuación muy buena, concedida a la vez a los lectores y a su periódico, pero todavía se puede mejorar. Se podría, en fin, ironizar sobre la contradicción entre la baja continua de ventas de la prensa regional, fenómeno que no evita Ouest France, y la utilización por parte de este periódico de su posición dominante como resorte publicitario. Queda que si los volúmenes disminuyen, las jerarquías permanecen. La prensa regional, ya sea diaria (PDR) o semanal (PSR), constituye la forma de información escrita la más leída en Francia, hacia tal punto que uno ya no se sorprende de que en este país, reconocido por su centralización, el diario más vendido sea un regional que no cubre más que tres de las veintidós regiones metropolitanas ${ }^{2}$. A pesar de la aparición de nuevos competidores (periódicos gratuitos en las grandes ciudades, Internet en todos partes) y el envejecimiento del lectorado, a pesar de las incertidumbres del mercado publicitario, la disminución del poder adquisitivo y la evolución socio-demográfica de territorios, la PDR continúa siendo leída masivamente, aunque sea un poco menos que antes, mientras que la PSR está muy bien implantada en una gran parte del territorio ${ }^{3}$.

En este contexto, la pregunta que se plantea este artículo es tan simple en apariencia que es ineludible para el estudio de la prensa regional contemporánea. Aquélla abre dos dimensiones iniciales ligadas a dos lecturas posibles del término «¿por qué?». Para empezar, la cuestión de elección: ¿cuáles son las razones que llevan a leer un periódico regional y ese periódico en particular? A continuación, la pregunta de la intención: leer, ¿pero, por qué leer? ¿Qué se busca en el periódico local y con qué propósito? Preguntárselo así, es volverse hacia el lectorado de la prensa regional, muy a menudo olvidado, aunque su estudio es también necesario para la comprensión de las apuestas de la prensa local, del análisis de la organización de empresas de prensa, del contenido de sus publicaciones, de la trayectoria de sus periodistas y del contexto socio-económico de la producción de la información. Este trabajo, proveniente de mi tesis (Ballarini, 2010), representa uno de los aspectos dentro de una reflexión más larga sobre el concepto del espacio público, partiendo del libro fundador de Jürgen Habermas

1 La letra pequeña de la publicidad menciona: «Estudio EPIQ, período 2007-2009, lectores regulares y ocasionales». No se trata pues, de aquellos que leen cada día el diario. En comparación, el informe de periódicos difundidos sobre población es, en Côtes-d’Armor, de 1,6 de cada 10 en el mismo periodo (media de difusión total de 94.000 ejemplares diarios para una población de 581.000 habitantes - cifras OJD e INSEE).

2 Medios de Ouest France en 2010: tirada de 850.000 ejemplares por día, difusión total 780.000 ejemplares, de los que 757.000 son vendidos. Le Figaro tiene 325.000 ventas diarias, Le Monde tiene 315.000 (cifras OJD).

$3 \mathrm{Si}$ bien no cubre la totalidad del territorio nacional, y poco o nada las grandes ciudades, la PSR está casi al nivel de las revistas de información (difusiones totales respectivas 87 y 106 millones de ejemplares anuales en 2010, cifras OJD). Esta permanece sin embargo ausente de los discursos nacionales, ya que esta muy buena audiencia acumulada es el resultado de una multitud de periódicos con especialización geográfica impulsada. 
(1993) y proyectando sus diversas apropiaciones por las Ciencias de la Información y de la Comunicación.

El terreno que se toma en cuenta en este estudio mezcla las aproximaciones cuantitativa y cualitativa. Un análisis de contenido de 1.651 artículos de PDR y PSR bretona se ha llevado a cabo, para empezar, con el fin de comprender qué «mundo» da a leer la prensa regional. En apariencia, la prensa regional francesa provee una información neutra y diversificada.

Pero en los hechos, la estructura de la información local en Francia aparece como orientada por una visión del mundo que privilegia la estabilidad y la tranquilidad sociales. Ahora bien, el mundo es complejo, hecho de interrelaciones que operan permanentemente y a largo plazo. De estos procesos, la prensa regional no retiene más que una sucesión de micro eventos sin causa ni consecuencia. Así, desvía la atención de mecanismos profundos de la sociedad para atraerla sobre una construcción simplificada al extremo de las relaciones sociales. Es por eso que propuse, como resultado de este estudio, describir el principal mecanismo en funcionamiento en la prensa regional, como consistente literalmente en divertir (Ballarini, 2008).

A continuación, realicé 20 entrevistas con habitantes del Pays de Saint-Brieuc sobre su relación con los periódicos locales, su lugar con respecto a otros medios y otras formas de informarse, así como sobre los procesos de constitución de opiniones. Los 24 encuestados fueron elegidos por sus muy diversos perfiles tanto socio-demográficos como mediáticos (de no lector a lector cotidiano de varios periódicos). La apuesta era entonces confrontar la visión que los habitantes tienen de la prensa local con la constatación obtenida por el análisis de contenido de esos periódicos. De esta manera, se hacía posible reparar en indicios de la estructura y del funcionamiento de los espacios públicos locales.

En efecto, la prensa regional explica su éxito por su capacidad de ser la mejor animadora del espacio público local, de la que sería el espejo fiel, difundiendo las más detalladas informaciones así como los debates más vivos. El espacio público se concibe entonces como un lugar transparente de circulación de ideas y noticias, cuya frecuentación permite a cada uno forjarse una opinión. Esta concepción, que es a la vez aquella de Habermas y muy próxima a los mitos profesionales de periodistas, es evidentemente gratificante para la prensa local. Nada indica, sin embargo, que corresponde, a priori, a las razones por las que los lectores compran esos periódicos, ni a la percepción que tienen del ecosistema mediático local y nacional. El desfase entre la visión del mundo difundida por la prensa local y la vida cotidiana de sus lectores deja incluso pensar lo contrario - y por tanto, esos periódicos continúan vendiéndose muy bien. En estas contradicciones aparentes parece pertinente interrogarse sobre el lugar que ocupa hoy la prensa local en el espacio público, sin cesar recompuesto por

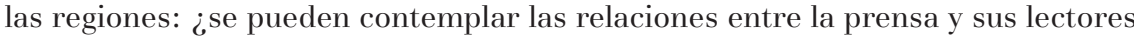
en términos de espacio público, y si es así, qué definición dar a estos espacios 
públicos? Para intentar responder a estas preguntas, este artículo se ciñe para empezar a la cuestión de la elección del periódico leído. Después, al modo de leerlo, en fin, a su rol dentro de la circulación de ideas y noticias.

\section{Uno no elige su periódico preferido}

\subsection{El papel primordial de la familia}

El Pays de Saint-Brieuc, centrado alrededor de la capital de provincia de Côtesd'Armor (Bretaña, Francia), está cubierto por tres periódicos de información general: dos diarios, Ouest France y Le Télégramme y un semanario, Le Penthièvre. De los lectores encuestados, pocos son los que no leen únicamente la prensa local, puesto que si uno no la lee regularmente, es frecuente encontrarla en el trabajo, con la familia o entre conocidos.

Existen así un millar de ocasiones en la vida diaria para poder tener entre manos un periódico regional. Por lo tanto, las razones que hacen que cada uno lea un periódico más que otro - es decir, la mayor parte del tiempo, Ouest France más que Le Télégramme, Le Penthièvre en una lejana tercera posición- son, en cambio, poco numerosas. Tienen, además, en común que estas decisiones casi nunca las toma conscientemente el lector, como sí se haría con la adquisición de una bicicleta después de haber probado varias.

La explicación que se da más a menudo remite la elección del periódico leído a la generación precedente: el hábito de leer por herencia familiar es hoy la más prometedora. Aquí no hay una elección propiamente dicha, sino la aceptación más o menos consciente de decisiones o hábitos de los padres. Estas se discuten menos en el caso de los encuestados que obtienen su periódico directamente a través de sus padres, ya sea porque son aún jóvenes y viven todavía con ellos, o bien, porque lo leen o recuperan su suscripción cuando ellos fallecen. Del mismo modo, el alcalde de una comunidad rural, a quien su función le impone una lectura utilitaria de tres periódicos, cita en primer lugar la familia: «Yo leo en la alcaldía, mi padre lo tiene, mi suegra también, yo lo tengo siempre en casa, es de uno o de otro. Jamás me aboné a Ouest France y lo he leído toda mi vida. Esto forma parte del patrimonio...».

\subsection{Lecturas obligatorias o por defecto}

El hábito de la lectura heredada de la familia ciertamente no señala una elección deliberada, pero se trata de una norma, que por ser muy eficaz, no parece menos suave y natural que evidente. Es otro tipo de norma más imperativa, pero también menos frecuente, que se impone en muchos de los encuestados: la obligación profesional. El alcalde antes citado, un secretario general de la alcaldía así como un encargado de asuntos culturales de la ciudad de Saint-Brieuc tienen en cuenta esta motivación. Los dos primeros leen los tres periódicos, la tercera se 
conforma generalmente con la revista de prensa preparada cada mañana por los servicios de la alcaldía para verificar que las conferencias de prensa que organiza y los eventos a su cargo, o que las colaboraciones o inserciones que ella misma fomenta, están presentes en las columnas de los periódicos locales. Si sus horarios no le permiten esperar la revista de prensa, consulta las web de los diarios - en el momento de la encuesta, Le Penthièvre todavía no tenía-. Hay que precisar, sin embargo, que estas formas de lectura obligatorias por la actividad profesional no se imponen sobre terreno virgen: cada uno de los tres encuestados tenía una práctica de lectura cotidiana antes de que sus funciones les obligaran.

Existe, en fin, una tercera forma de no elección de un periódico regional, que concierne al caso donde un título en particular se impone por defecto, pudiendo ser éste de un orden geográfico o temporal. El defecto es geográfico cuando uno lee el periódico que está disponible donde uno se encuentra: en la cafetería, en un restaurante universitario, en un café; o cuando, originario de una región cubierta por un diario particular, uno se pone a leer lo que se difunde sobre el sitio donde uno habita. Es temporal cuando adapta sus lecturas a su horario - del día, de la semana o de diferentes etapas de la vida-. Así, uno de los encuestados, jurista de una asociación, leía Le Monde todos los días durante sus estudios de derecho. Al inicio de su carrera profesional, soltero, viviendo en las afueras de París, leía los semanarios generalistas, particularmente L'Express. Hoy, viviendo en pareja, con dos hijos e instalado en una pequeña aldea rural de la que aprecia las intensas relaciones vecinales, tiene menos tiempo para dedicarle a la prensa y no compra más que el Ouest France una vez por semana, el día de la aparición del programa televisado.

\subsection{La lectura como necesidad}

A la no elección, a veces se agrega el sentimiento de una evidencia, sino de una necesidad, de leer la prensa, que puede tomar muchas formas. La primera es casi tautológica: hay que leer porque hay que leer, porque es beneficioso leer y nada puede reemplazar esta actividad.

Son los adultos mayores encuestados quienes se expresan así, quienes toda su vida han leído la prensa regional y pueden llegar a acumular varias décadas abonados a este tipo de prensa. Ellos pertenecen casi todos al grupo de personas con más de 65 años, el único grupo donde la lectura de la prensa cotidiana aumenta todavía y que constituye la primera generación descrita en el último estudio sobre las Prácticas culturales de los Franceses.

Una generación que nació antes de la Segunda Guerra Mundial y que creció en un mundo donde lo escrito dominaba, que conserva un apego muy fuerte a la prensa escrita y que no pone en práctica, por lo tanto, el uso intensivo de la televisión (Donnat, 2009).

La evidencia de que hay que leer, puede llegar hasta convertirse en un tipo de obligación moral, vinculada a la profesión ejercida, en este caso el oficio de 
profesor. «Da pena imaginar que ciertos profesores puedan no leer la prensa regional. Es dejar de lado una gran parte de eso que constituye la vida de sus alumnos», afirma un profesor de colegio. No leer el periódico regional es como estar apartado del entramado social, rechazar participar en la vida local y lo que es peor, renunciar a comprenderla. Ahora bien, ¿cómo enseñar bien sin conocimiento, no sólo de ideas, programas y técnicas que uno está encargado de transmitir, sino también del contexto que rodea el mismo acto de enseñar, y particularmente de la multitud de interacciones sociales en las que los alumnos están involucrados y que influye en sus capacidades de recepción, de aprendizaje, de restitución de contenidos y de reflexión sobre su entorno? Ninguna regla escrita o tácita obliga a un enseñante a leer la prensa. Pero de acuerdo con este punto de vista, una cierta concepción de su ética profesional puede y debería sin embargo obligarle. La articulación entre la causa y los efectos resulta ser, por tanto, en gran parte artificial. Para empezar, porque la prensa no es más que un espejo muy imperfecto de la vida local, es ahí de lo que los encuestados que la leen asiduamente son por otro lado conscientes. Después, porque esta obligación moral no es el principal resultado de su práctica personal de lectura, estando incluso ligada a costumbres familiares reforzadas por el militarismo sindical y político. Afirmar que la necesidad de leer un periódico regional debería parecer evidente a todo enseñante, constituye más bien de hecho un reproche en contra de los colegas a los que se sabe o a los que se presume, lectores menos asiduos que ellos y de los que lamenta su desmovilización y la falta de inversión crecientes en los proyectos pedagógicos y sindicales. Más que el instrumento de una práctica profesional integrada a la vida ciudadana, la prensa local juega aquí el papel de barómetro de la despolitización de una profesión.

Más allá de consideraciones morales o profesionales, el periódico regional puede todavía imponerse por dos razones: por su importante tasa de penetración, que constituye una especie de periódico oficial que registra las minutas de todo lo que pasa localmente ; o por el placer que su lectura procura - este último caso no se cita más que una sola vez.

\subsection{Hábitos raramente puestos en marcha}

No elegido por sus lectores, el periódico regional se impone por herencia familiar, obligación profesional o, más prosaicamente todavía incluso por defecto. La lectura de un periódico más que otro se convierte enseguida en un hábito totalmente anclado, que el periódico competidor parece difícil de leer o desordenado; el ojo se orienta tanto con el despliegue del periódico como en cada una de sus páginas ${ }^{4}$. Salvo caso excepcional, esta costumbre no es jamás puesta en duda ni siquiera ponderada. Al contrario, se constata que los intereses parti-

\footnotetext{
4 Una suscrita a Ouest France: « Mi prima tiene Le Télégramme. Cuando se lee... uno se pierde. No sabemos leer otro periódico». Una compradora cotidiana de Télégramme, a propósito de Ouest France: «Uno tiene problemas para leerlo. No se sabe por qué trozo tomarlo». Aunque las cuestiones visuales (formato, paginación) no son de las que crean hábitos de lectura, no hay que descuidar el papel que tienen en el fortalecimiento de estas costumbres por el formateo del ojo del lector.
} 
culares de lectura (obituarios, páginas deportivas...) refuerzan la costumbre: se tiene la impresión de que en su periódico «preferido» los temas que más le interesan son los que están mejor tratados siempre. Por lo tanto, si los encuestados son numerosos, al evocar el diario que ellos no leen, raros son aquellos que verdaderamente han comparado Ouest France y Le Télégramme. La inmensa mayoría se contenta con evocaciones vagas o de lo que se dice. De hecho, para ellos la cuestión no parece darse: una costumbre bien anclada acaba por parecer natural y hasta se apegan incluso a los defectos de su periódico, considerando en última instancia, que si el propósito de ambos periódicos es más o menos similar, es tanto mejor continuar leyendo aquél al que están acostumbrados.

Es significativo hacer notar que un solo encuestado ha cambiado de periódico en el transcurso de su vida como lector. Este militante ecologista, aunque irritado por la «ideología suave», "puramente centralista y conservadora» que Ouest France difunde según él, se acomodó mucho tiempo a este periódico porque lo encontraba «muy muy bien hecho ». Hasta que el tratamiento de las huelgas de la primavera del 2003 contra la reforma de las pensiones le escandalizó, lo que le condujo a la suspensión de su suscripción. Desde entonces lee Le Télégramme, que juzga «tampoco mal hecho». Más allá de la aparente motivación política de su decisión, aquí también se trata de otro tipo de «elección negativa» o por defecto puesto que en esa época no leía Le Télégramme y no sabía cuál fue la actitud de este periódico respecto a las huelgas del 2003 y mucho menos si el tratamiento de la información le habría convenido más que el de Ouest France. El cambio no fue impulsado por una comparación, sino por una ruptura: Ouest France le desagradó bastante una vez, pero como él deseaba seguir leyendo un regional no le quedaba otra opción que Le Télégramme.

No le habría sido posible realizar este paso en la mayoría de las regiones francesas, donde la PDR desarrolló monopolios locales muy amplios. Pero en una región como Bretaña, donde la alternativa existe entre dos diarios, se podría esperar que más lectores tomaran el mismo camino. El peso de las rutinas familiares sería tan fuerte que impediría superarlo, ¿no es así? Los periódicos serían percibidos como totalmente equivalentes lo que hace bastante costoso cambiar sus costumbres para aprender otro periódico, ¿es decir, dominar una nueva forma que no hace sino vestir el mismo fondo? Sea cual sea la respuesta, merma la visión idealista de pluralismo de la prensa regional y de la elección racional de lecturas en función de intereses bien comprendidos.

\section{Las dos maneras de leer un regional}

\subsection{Una lectura geográfica}

Raros son los lectores que declaran leer el periódico local en su totalidad. Incluso los jubilados, que tendrían a priori el tiempo de hacerlo, echan sólo un vistazo a ciertas secciones. De hecho, se apuntan dos maneras de leer la prensa 
regional: la más citada es la geográfica, la segunda es la temática. La lectura geográfica hace referencia a las diferentes escalas territoriales tal como aparecen a lo largo del periódico o en la percepción de sus lectores. La comunidad de residencia es a menudo la primera destinación del lector. Los niveles regional y nacional son consultados acto seguido en función de intereses personales y profesionales, así como del tiempo disponible. Los lectores hablan igualmente mucho de «local» o de «páginas locales», concepto vago que, según se participe en algo, despierta su interés, o al contrario les hace mirarlo de lejos, tanto atrae como repele. A primera vista los habitantes rurales se muestran más ávidos de lo «local» que los urbanos, fácilmente despectivos de los concursos de bolos y otras kermeses. Mientras que estos pequeños juicios muestran, de manera terminante, que sobre todo cada uno se hace su propia idea de localidad, que «lo» local es antes que todo un local particular, un local de entre otros. Una pareja de jubilados que viven en una capital de provincia declaran interesarse sobre todo en «SaintBrieuc y sus alrededores [...] Las páginas interiores, eso nos interesa menos, forzosamente». ¡Por lo tanto, Saint-Brieuc y sus alrededores bien que forman parte de sus páginas interiores! Lo mismo ocurre con el pueblo costero del que son originarios, donde pasan todos sus veranos y cuyas noticias les gusta recibir. Estos municipios forman parte indiscutiblemente de «su» local, y es por esto que paradójicamente esas noticias no son percibidas como «interiores». En efecto, las páginas de un periódico ya no le parecen nunca más interiores a un lector que cuando son exteriores a sus preocupaciones.

La cuestión es más bien saber si aspectos del espacio vital de una persona, de una pareja o de una familia pueden trasladarse a la lectura del periódico. A las impresiones, a los desplazamientos diarios y semanales, a las actividades del trabajo, de la conducta en el hogar y en el ocio, en las relaciones familiares, amistosas y profesionales: habría entonces que encontrar un equivalente en las secciones del periódico. En apariencia, la operación parece posible, en tanto que la lectura de un diario regional permite abrazar la totalidad del «mundo». De la aldea más pequeña a la actualidad internacional, pasando por las secciones deportiva y de espectáculos, la diversidad de escalas y de temas abordados es ciertamente la mayor de toda la prensa.

Las apariencias son sin embargo en gran parte engañosas. El mundo que el periódico regional da a leer está muy alejado del que viven sus lectores potenciales. Cada evento que el periódico cuenta parece tomado como un todo minúsculo e independiente, extraído de todo contexto e ignorante de procesos que recomienzan sin cesar de construcción de identidades y de pertenencia a un territorio. Y si este mundo parece extremadamente diverso, no deja de excluir importantes esferas de la vida social - he demostrado, por ejemplo, que el paro allí era casi invisible (Ballarini, 2008) — . Esta visión de la información, que constituye la parte agradable a las micronotabilidades y al conservadurismo social negando toda referencia al fracaso, está además sometida a un recorte

5 Esto es menos cierto para los semanarios regionales que raramente incluyen secciones que no estén dentro de su zona de cobertura. 
territorial que parece natural a fuerza de costumbre, pero que no es nada más que arbitrariedad. Los diarios y la mayor parte de los semanarios regionales utilizan, en efecto, como base de su presentación, en una sola sección, la asociación commune-canton ${ }^{6}$. Por falta de compartimientos y espacio para repartirlos allí, se ciegan ante las escalas de la intercomunalidad y del Pays ${ }^{7}$, donde tienden por tanto a concentrarse los poderes políticos y económicos locales. Al aparente rigor de esta edición se agregan notables excepciones : sin estar ausentes de las páginas locales, el deporte y la cultura disponen, así como los anuncios clasificados y los obituarios, de secciones dedicadas a territoriales, situados el final del periódico. No hay que olvidar la cuestión de la zona de cobertura de los periódicos, que contrariamente a lo que está anunciado, resultan más bien luchas por la conquista de territorio más que estrategias identitarias o de representación (Tétu, 1995 ; Le Bohec, 1999). Al mismo tiempo que los niveles locales de territorio no dejan de complicarse, entrañan a menudo la confusión de los lectores y el periódico no hace nada para disiparla, al contrario, la acentúa por su incapacidad de adaptar su edición a la realidad de la vida cotidiana.

\subsection{Una lectura temática}

Cuando no está espacialmente diferenciada, la lectura del diario regional es temática: deportes, información-servicios, ocio o tiempo libre, etc. La mayor parte de estos temas pueden, sin embargo, incorporarse al nivel local. Combinados con éste, motivan el abono o la lectura cotidiana. Solos, conducen a una compra regular: los lunes por los resultados deportivos, el viernes o el sábado por el programa de festejos del fin de semana o el suplemento de televisión; o a una compra puntual, para encontrar, por ejemplo, la foto de sus hijos después de una salida escolar. Los obituarios, con frecuencia citados, continúan siendo una motivación importante que impone la regularidad. Pero contrariamente a las ideas recibidas, esta motivación no es jamás principal ni exclusiva: los obituarios se mencionan siempre junto a una o varias secciones.

En esta constatación habría para desesperar a un periodista apegado a su oficio (o a la representación que él se hace del mismo): lo que los lectores buscan, son los resultados de partidos de fútbol, el anuncio de espectáculos venideros, los horarios de las mareas, de la permanencia del diputado o de la biblioteca, en breve, todo menos el trabajo periodístico, todo lo que no es «noble». Quedarse sólo con esta constatación sería despachar el trabajo y olvidar que estas respuestas temáticas no vienen allí tampoco jamás solas. En efecto, la vida práctica no está separada de la vida ciudadana, y las informaciones detalladas de servicio

6 En Francia, la «commune» es la división administrativa que corresponde al municipio, y el «canton» a un conjunto de «communes».

7 Las intercomunalidades son reagrupamientos de municipios, llamados comunidades de municipios o comunidades de aglomeración en función de su tamaño. Los Pays son «territorios de proyectos», tal y como están definidos por la ley del 25 de junio de 1999 (llamada Ley Voynet). Se considera que corresponden a escenarios de vida y de actividad, pero son, administrativamente hablando, reagrupaciones de intercomunalidades avaladas por las prefecturas — su creación está pues sometida al acuerdo del Estado. 
del periódico forman parte de un todo indisociable. Es por ejemplo, al buscar informaciones prácticas cuando uno encuentra artículos vinculados a su vida profesional o a sus centros de interés, cuyo contenido luego reinvertirá en sus reflexiones y conversaciones.

Sin que se puedan asimilar estos procesos a una discusión razonada sobre el interés común, y sin alcanzar pues el ideal compartido por periodistas y teóricos del espacio público, hay sin duda que reconocer que la circulación de las ideas y de las noticias se hace también, y posiblemente sobre todo, por estos canales diarios y rutinarios cuya prensa local constituye un elemento importante.

Un buen ejemplo de estas aparentes contradicciones reside en los numerosos casos donde el periódico regional no se lee tanto para aprender alguna cosa, como para encontrar algo que ya se sabe. No se trata aquí de un interés personal, político o profesional hacia un tema en particular que va a conducir al lector a estar atento hacia artículos que le conciernen y a buscarlos. Sino que es el hecho de saber que tuvo lugar tal evento preciso lo que hará comprar el periódico con la esperanza de leer la noticia completa. Esta práctica es extremadamente frecuente y reúne en parte las motivaciones ya mencionadas: uno busca la foto del partido de fútbol del equipo de su hijo, o el artículo que da cuenta de la manifestación en la que participó. Desde este punto de vista, la búsqueda de lo que uno sabe previamente, es una de las motivaciones principales de la compra de la prensa regional, siendo una de las más paradójicas.

¿Por qué querer leer y (re)ver lo que uno ya sabe? Tal vez por la precisión que aporta el periódico, por la «oficialización» que él hace del evento, la legitimidad que le confiere al consagrarle un espacio, un texto, una foto. Por eso, esta motivación no es más que raramente citada como tal por los encuestados, permaneciendo en general como implícita. No se vuelve explícita hasta que se aborda con ejemplos precisos que corresponden para el lector a una práctica regular de orden crítico. Así la encargada de asuntos culturales o el militante sindical desarrollaron un uso consciente del periódico que consistía en no buscar simplemente si el periódico habló de tal o cual acontecimiento, más bien de cómo habló de eso. Un secretario general de ayuntamiento declara: « existe la información, los hechos, y luego algunas veces la interpretación que el periodista da, que es un hecho en sí mismo. [...] Es por esto que algunas veces es importante que me refiera a pesar de todo al periódico, porque aquel hecho lo tendré únicamente si leo el periódico ». Nada o casi nada de lo que aparece en el periódico que concierne a su municipio le es previamente desconocido, pero su lectura depende de una apuesta doble. En primer lugar la búsqueda de una parte de justificación, incluso de reconocimiento de su propia acción, confundida en una forma de sinécdoque con la acción conducida por el ayuntamiento -lo demuestran sus largas exposiciones sobre el "sentimiento de injusticia » resentido a raíz del tratamiento de tal o cual asunto, donde el ayuntamiento había sido, según él acusado, sin razón-. Contiene también la elaboración de un discurso sobre el periódico a partir del periódico en sí mismo, y a través de 
la confrontación entre lo que da a leer y la « realidad de los hechos » tal y como supone conocerla. Si parece natural que los encuestados, que son los que están más en contacto con el periódico y los periodistas (por sus actividades profesionales, militantes o asociativas) desarrollen de una manera formalizada este tipo de discurso, no es sin embargo su exclusividad. Basta con haber asistido a una fiesta campestre para después leer un informe que insiste en tal aspecto que uno considere secundario para que se instale este tipo de distancia, que jamás aparece en primer lugar en lo dicho por los encuestados, pero que siempre está listo para ser ilustrado con ejemplos vividos.

\section{Prensa local y espacio público}

\subsection{El reflejo imperfecto de una vida compleja}

Se observa muy bien este fenómeno, cuando uno se interesa en la manera en que los lectores perciben la calidad de la prensa local. Los primeros temas que vienen a discusión son siempre positivos: «Está bien hecho este periódico». Neutro, respetuoso, atento a no acusar indebidamente a personas y abierto a las acciones que se tendría ganas de dar a conocer, tal es el retrato global y espontáneo del periódico regional. Pero no queda intacto mucho tiempo y, tan pronto como el periódico ya no se considera como una entidad, sino como un conjunto de artículos o de individuos que contribuyen a fabricarlo, se apuntan reservas y críticas a veces muy argumentadas. El lector, sin embargo, es a menudo indulgente: un error puede pasar, el periódico tiene en general buena fe - la prueba es que rectifica en una edición posterior si se ha equivocado. Un anuncio de concierto en que aparece en el municipio equivocado, los nombres de los entrevistados invertidos dentro de una encuesta, esto es ciertamente irritante, sin embargo «no es dramático». Más molesta es la propensión de los periódicos a enfocarse hacia ciertos aspectos de la vida local, con riesgo de olvidar otros más dignos de interés. Hay que mirarlo en Internet. «En todo caso, en Ouest France no hablan de eso", afirma un operador de control técnico automóvil, un gran aficionado de deportes de motor.

A partir de estas recriminaciones puntuales o más regulares, pueden formarse de todas maneras críticas generales, que si bien son menos frecuentes, ponen por contra en tela de juicio el funcionamiento de la prensa local. Para empezar se le acusa de falta de curiosidad. «Sobre la vida local Ouest France no tiene nada, en fin... aparte de eventos. Son sólo artículos sobre eventos». El tipo de eventos al que se refiere este auxiliar de laboratorio de treinta años no es el que provoca un cambio de ritmo en el periódico y «marca una nueva temporalidad, que altera la información pasada y la que está por venir» (Bensa y Fassin, 2002), como se puede concebir en sociología o en antropología. Al contrario, el evento aquí es totalmente previsible y se inscribe en la continuidad de rutinas microlocales. Se trata del concierto, del pleno del ayuntamiento, de la junta general de una asociación o de los horarios del cine, que son acontecimientos sólo porque 
aparecen en el periódico. Es aquí a donde se dirige el reproche, a esta pereza del periódico que se contenta con las invitaciones que recibe, más que en ir a buscar por sí mismo los elementos que le permitirían elaborar, construir eventos originales. El «estándar de hecho» (Mouillaud y Tétu, 1989) y los «lentes» de los periodistas (Bourdieu, 1996), que hacen que no pase nada en el periódico más que eso que el periódico puede esperar que pase, no son solamente conceptos: sus efectos son bien percibidos por los lectores.

Peor que la falta de curiosidad: la colusión. Son numerosos los lectores que reprochan a los regionales su línea consensual, o los acusan de trabajar en la perpetuación del orden establecido, pero apenas dan pruebas de sus intenciones. Sin embargo, índices graves y concordantes sostienen estas tesis. Así, un profesor de instituto ha sido testigo dos veces de la influencia directa de dos campos vecinos del periodismo sobre éste. La economía para empezar: miembro de un club deportivo que organiza competiciones veraniegas de vóley playa a nivel europeo, constató que, después de la primera edición, Ouest France no había escrito ni una sola línea. ¿Por qué la integridad de la publicidad mediática había sido comprada por Télégramme? Es forzoso constatar que «el año siguiente, ellos dieron la publicidad a Ouest France, y la información ahí sí estaba». La política, también: después de una Semana de la prensa ${ }^{8}$, algunos de sus alumnos habían emitido, en un artículo publicado por Ouest France, críticas sobre su nuevo gimnasio. El Alcalde en persona había llamado entonces al director del instituto para quejarse. Incluso si los lectores nunca tuvieron conocimiento de esta recriminación (bajo la forma de una rectificación, por ejemplo), es reveladora de la proporción de las relaciones ordinarias entre la prensa local y política municipal: «El responsable de la agencia Ouest France en Saint-Brieuc, no va a molestar al alcalde. Esto hace reflexionar». Y esto puede, contrariamente a los errores de nombres que uno perdona, mermar seriamente la credibilidad del periódico.

\section{2. ¿Para qué sirve la prensa local?}

Sin embargo, cuando se pregunta a los lectores si la prensa regional responde a sus expectativas, ellos son todavía muy positivos. De nuevo, la satisfacción prevalece - y de lejos - sobre la crítica. Este juicio se amplifica en quienes, en vacaciones o durante un desplazamiento tuvieron la ocasión de comparar «su» periódico con otro regional. «Hay que haber leído otros periódicos cuando usted sale a pasear a otros sitios de Francia, para darse cuenta que Ouest France, finalmente, no es tan malo como ése», explica un cajero de La Poste. Habría que poder poner esta comparación en perspectiva con la experiencia de lectores de otras regiones, pero es probable que el periódico que se acostumbra a leer

8 La Semana de la prensa y de los medios en las escuelas se organiza cada primavera por el Centre de Liaison de l'Enseignement et des Médias d'Information (CLEMI), que depende del Ministerio de Educación nacional. Esta manifestación permite a los alumnos de todos los niveles descubrir el funcionamiento de los medios y en ocasiones, publicar artículos. 
cuente con un a priori favorable. Sus defectos se funden con la lectura cotidiana, mientras que en los periódicos que uno descubre, los defectos saltan a la vista mucho más, ya que hablan con menos familiaridad de su territorio, lo que permite que la atención se centre en cuestiones menos personales.

Si el ejercicio comparativo tiende naturalmente a valorizar lo que nos es próximo, posiblemente estaremos más sorprendidos al constatar que son los encuestados los más comprometidos con la izquierda, es decir, los más susceptibles de cuestionar la orientación de los periódicos locales hacia la estabilidad social y el conservadurismo político, quienes declaran encontrar lo que buscan en estas publicaciones que, finalmente, corresponden a sus expectativas. ¿Pero hay que sorprenderse verdaderamente? O más bien, ¿puede uno asombrarse sin antes preguntarse para qué sirve la prensa regional para aquellos que la leen? Los militantes sindicales y políticos no esperan que la prensa regional les provea de argumentos que vayan en su dirección y que tiendan a apoyar su visión del mundo. Es por eso que encuentran allí efectivamente lo que buscan, que es otra cosa: Como otros lectores, esperan de su periódico regional informaciones prácticas y factuales, una buena cobertura de su territorio y un relativo tono de neutralidad.

La percepción del periódico como «apertura sobre el mundo» es en cuanto a sí misma marginal. Más allá de algunas figuras retóricas convencionales, el periódico tampoco es aprehendido como un instrumento de participación en el debate público. La función de la prensa regional parece emparentarse más bien con el mantenimiento de un entramado social elemental, que pasa por la difusión en el seno de la comunidad local de avisos de nacimientos, defunciones, de reuniones diversas. Los regionales, que construyeron su modelo sobre una línea consensual y despolitizada tendente al establecimiento de monopolios locales, desafían toda marca política, y consiguen en gran medida conservar la indecisión, si no la confusión, sobre este tema. Siguiendo al lector encuestado, es así que unas veces Le Télégramme y otras Ouest France, se perciben como más bien de derechas o de izquierdas - y podemos muy bien siendo de izquierdas, encontrar Le Télégramme más a la izquierda que su competidor, sin dejar por eso de leer Ouest France.

El ideal del espacio público desarrollado por Habermas (1993) comparte con los mitos profesionales de periodistas esta concepción de la prensa como lugar simbólico de circulación de ideas que desemboca en la construcción de una opinión pública por el intercambio racional de argumentos. Pero para que este ideal pueda tener oportunidad de realizarse, la prensa tendría que constituir una especie de servicio público que asumiera el desafío de difundir de manera rigurosamente neutra informaciones exclusivamente políticas en el sentido estricto del término. Evidentemente éste no es el caso, no más en la prensa nacional que en la regional, y «sólo la fe etnocéntrica en el mito de la "opinión personal" que "se hace" al precio de un esfuerzo permanente para informarse y mantenerse al corriente, puede hacer ignorar que el periódico (cuando se lee uno) no es más que un periódico de opinión sólo para algunos» (Bourdieu, 1979: 515). 
El ideal del espacio público implica igualmente la reciprocidad. Ahora bien, en los hechos la reciprocidad no existe. El lector, destinatario del periódico, no se vuelve jamás un destinatario en el sentido en el que Habermas lo entiende, es decir, en tanto que persona privada haciendo un uso público de su razón. Raros son aquellos que envían una carta al correo de lectores, puesto que hay una interiorización del hecho de que no es al lector a quien le corresponde escribir en el periódico. Cuando esto sucede, las intervenciones son sistemáticamente filtradas. Los correos son seleccionados y editados. Sobre el sitio de Internet los temas de reflexión son impuestos, la selección y edición son igualmente posibles. Agreguemos también que cualquiera puede dirigirse al periódico: el profesor sindicalizado, el anterior jefe del centro de impuestos, el encargado de asuntos culturales, el alcalde. Sólo los encuestados, pertenecientes a clases sociales «letradas», acostumbrados a tomar la palabra en público o a utilizar el escrito de manera oficial intervienen en el periódico. Si el espacio público estuviera en la imagen de quienes pueden tener acceso para expresar su opinión, entonces habría que considerar que la ciudadanía es censataria y que el derecho de entrar en términos de colocación en el campo social es particularmente elevado. La «esfera pública burguesa» habermasiana merecería su denominación según su acepción más restrictiva, es decir que sería muy «burguesa», pero apenas «pública».

\section{Conclusión: Información y conversación}

La cuestión del correo de lectores es la única entre todas las abordadas durante las entrevistas que en verdad se escinde socialmente. En los juicios referidos a la prensa local, dentro de eso que los lectores buscan o perciben, factores determinantes habituales como el sexo o las categorías socioprofesionales no parecen jugar más que un papel menor. Ciertamente, el funcionamiento del periódico no es comprendido de la misma manera por el mecánico que no ha realizado estudios y asimila el periódico como una fábrica, que por el secretario general de la Alcaldía, que realizó estudios superiores, frecuenta a los periodistas todos los días, lee la prensa regional y nacional y posee un conocimiento global bastante preciso del regional (rol diferenciado por los corresponsales y los periodistas, los nombres de los responsables de la redacción, la existencia de un director departamental, etc.). Pero sus previsiones y observaciones que se refieren a lo que estiman una deformación de las informaciones por el periódico se confirman.

No escogido por sus lectores, siendo apreciado como un proveedor relativamente neutro de informaciones prácticas diversificadas, y criticado por su tendencia que se complace con la reproducción de las notabilidades: el retrato del periódico regional, así como las razones de leerlo (o no), aparecen extremadamente estables con el curso del tiempo, lejos de la tempestad que parece agitar las salas de redacción y los análisis de expertos autoproclamados. El lugar del regional se reduce, pero su función permanece. Las mutaciones actuales del campo 
periodístico están notablemente marcadas por la digitalización, el desarrollo de Internet y la persecución de los movimientos de concentración de capitales. Se traducen en una competencia recrudecida entre los diferentes medios de comunicación - competencia a la vez económica y simbólica, cuya apuesta es tanto ganar cuotas de mercado como imponer su legitimidad. Pero allá donde los periodistas y editores de prensa ven una competencia, y en ocasiones una amenaza, los lectores, en su experiencia cotidiana de consumación mediática, perciben más bien una complementariedad entre los diferentes modos de informarse de los que disponen. Ya que eso que une a todos los encuestados, lectores regulares u ocasionales de la prensa regional, es un hecho tan evidente como raramente tomado en consideración: el periódico no basta para conocer el mundo. Hay otros medios de comunicación, que se completan o se contradicen, el todo teje lazos complejos con uno de los fenómenos esenciales de la vida cotidiana, la conversación.

El sentimiento dominante entre los encuestados es por otra parte, que la conversación y los medios juegan un rol equivalente en el conocimiento del mundo. El reparto más frecuente ve las informaciones locales aportadas por la conversación y las informaciones concernientes a las escalas superiores de territorio, aportadas por los medios de comunicación. Las conversaciones con los colegas de trabajo son por ejemplo, una fuente importante de información local. Sea que el colega que le enseña constituya un testimonio o un actor del relato o de la anécdota considerada, sea que él lo aprendió de cualquier otro o de un medio. Esta representación esquemática esconde sin embargo grandes matices, de los cuales no parece destacar ninguna regularidad, permitiendo atribuirle las variaciones a los determinantes sociales habituales. Los encuestados que declaran aprender así más cosas sobre el mundo a través de la conversación, tienen ciertamente una vida social rica, conocen muy bien su barrio o su municipio, o forman parte de redes militantes - pero ellos comparten esas características con la mayor parte de aquellos para quienes la fuente principal de conocimiento del mundo es la prensa, mientras que ninguna consideración generalizable de ingresos, de profesión o de forma de vida los distingue. Una búsqueda cuantitativa desembocaría tal vez en el establecimiento de regularidades estadísticas que la encuesta cualitativa no puede captar. Pero sea lo que sea lo que estas puedan revelar, no dudarían del hecho de que la constitución de la opinión personal, la reflexión sobre los problemas inmediatos como sobre las apuestas comunes no pueden ser llevadas únicamente por los medios de comunicación, que dan del mundo sólo una imagen muy simplificada y siempre son completados, a veces totalmente reemplazados por las conversaciones. No existe línea de compartimento de la información como hay unas líneas de compartimento de las aguas entre dos estanques vertientes: mientras que un río necesariamente fluye sobre un costado o el otro de una montaña, nadie es totalmente ciego y sordo a todo tipo de medio de comunicación, así como nadie está irremediablemente alejado de toda relación intersubjetiva. 
Escribir esto no implica que haya que renunciar a todo lazo entre prensa local y espacio público, pero invita a reconsiderar el marco de lo que comúnmente es admitido como constituyente del espacio público. La concepción clásica del espacio público, considerado como el lugar simbólico de circulación de las ideas que permiten un uso público de la razón mediado por los periódicos, está en efecto muy alejada de las constataciones realizadas sobre el terreno. La prensa regional no es el órgano neutro a través del cual cada ciudadano puede expresarse y gracias al cual forja su opinión. Por contra, la prensa regional participa en el mantenimiento de un entramado social elemental, que pasa notablemente por la transmisión de informaciones prácticas y de informaciones detalladas. Este flujo de microinformaciones no es evidentemente suficiente para llevar a cabo el debate sobre las apuestas de interés general; es no obstante una de sus condiciones de posibilidad. Para que cada ciudadano esté en disposición de expresar y de confrontar opiniones y juicios sobre el mundo que le rodea, es en efecto indispensable que posea un cierto conocimiento factual y previo. La prensa regional no constituye, ni jamás ha constituido el espacio público en su totalidad sino que es ciertamente un elemento del mismo. A condición de salir de la visión ideal y normativa del espacio público iniciada por Habermas y de adoptar un enfoque dinámico y fragmentado, tal como el propuesto por diferentes autores (Dahlgren, 1995; François y Neveu, 1999; Miège, 2010; Calhoun, 1992; Negt, 2007) y que propongo renovar por el estudio de lo local y de las conversaciones (Ballarini, 2010).

Si el estudio de las mutaciones de la información y de los medios de comunicación locales no puede en efecto realizarse sin la de sus públicos, esta última no puede tampoco limitarse a cuestiones clásicas de recepción, que encierran la reflexión en un díptico medios de comunicación /públicos que borran una parte de la realidad social ${ }^{9}$. Se trata, con más amplitud, de abrir la concepción del espacio público a intercambios cotidianos, ya sean mediados o no, y donde la finalidad no es necesariamente política. Igualmente, pensar en estos intercambios dentro de la articulación entre las escalas de territorio (Lacoste, 1985) y en el contexto cambiante de procesos de socialización (Elias, 1997; Percheron, 1993), donde lo local es el lugar privilegiado. Lejos del corsé apremiante del ideal habermasiano, el espacio público se volvería un marco abierto del que la interdisciplinariedad reactivada permitiría comprender la circulación de las ideas y de las noticias así como la formación de las opiniones personales. Como lo sugieren Arendt (2002) o Lecercle (2004), el espacio público no es una institución inmóvil donde las reglas no permiten tener en cuenta que un cierto tipo de acción muy limitada, es, al contrario, el producto de la acción de temas insertados en las relaciones sociales. Es, partiendo de estas condiciones objetivas como se podrá abordar el estudio de espacios públicos sin cesar recompuestos por las regiones.

Traducción: Maru Garduño Barberena

9 Cf. Por ejemplo Goulet (2010) que vincula de manera notable conversación y medios de comunicación. 


\section{Referencias}

Arendt, Hannah (2002) [1958]. Condition de l'homme moderne, Paris: Pocket. Ballarini, Loïc (2008). Presse locale : un média de diversion. En: Réseaux, $\mathrm{n}^{\mathrm{o}}$ 148-149, 405-426.

Ballarini, Loïc (2010). L'espace public au-delà de l'agir communicationnel. Quatre renversements de perspective pour sortir des impasses du modèle habermassien, tesis doctoral en Ciencias de la Información y la Comunicación, bajo la dirección de Jacques Guyot, Unirversité Paris 8. En: http://tel.archives-ouvertes.fr/tel-00573282/fr/ [Consultada el 7 de septiembre 2012].

Bensa, Alban y Fassin, Éric (2002). Les sciences sociales face à l'événement. En: Terrain, $n^{\circ}$ 38. En: http://terrain.revues.org/1888. [Consultada el 7 de septiembre 2012].

Bourdieu, Pierre (1979). La Distinction. Critique sociale du jugement, Paris: Éditions de Minuit.

Bourdieu, Pierre (1996). Sur la télévision suivi de L’emprise du journalisme, Paris: Liber/Raisons d'agir.

Calhoun, Craig (dir.) (1992). Habermas and the Public Sphere, Cambridge, Massachussets/Londres: The MIT Press.

Dahlgren, Peter (1995). Television and the Public Sphere, Londres: Sage Publications.

Donnat, Olivier (dir.) (2009). Les Pratiques culturelles des Français à l'ère numérique. Enquête 2008, Paris: La Découverte/Ministère de la culture et de la communication.

Elias, Norbert (1997) [1987]. La Société des individus, Paris: Pocket.

François, Bastien y Neveu, Érik (dir.) (1999). Espaces publics mosaïques. Acteurs, arènes et rhétoriques des débats publics contemporains, Rennes: Presses universitaires de Rennes.

Gabszewicz, Jean y Sonnac, Nathalie (2010). Lindustrie des médias à l'ère numérique, Paris: La Découverte.

Goulet, Vincent (2010). Médias et classes populaires. Les usages ordinaires des informations, Paris: Ina éditions.

Habermas, Jürgen (1993) [1962]. L'Espace public, Paris: Payot.

Lacoste, Yves (1985) [1976]. La géographie ça sert, d'abord, à faire la guerre, Paris: La Découverte.

Le Bohec, Jacques (1999). Les stratégies territoriales des entreprises de presse en province. En: Sciences de la société, nº48, 177-194. 
Lecercle, Jean-Jacques (2004). Une philosophie marxiste du langage, Paris: PUF. Miège, Bernard (2010). L'espace public contemporain. Approche info-communicationnelle, Grenoble: Presses universitaires de Grenoble.

Mouillaud, Maurice y Tétu, Jean-François (1989). Le Journal quotidien, Lyon: Presses universitaires de Lyon.

Negt, Oskar (2007). L'espace public oppositionnel, Paris: Payot.

Pailliart, Isabelle (dir.) (1995). L'espace public et l'emprise de la communication, Grenoble: Ellug.

Percheron, Annick (1993). La socialisation politique, Paris: Armand Colin.

Tétu, Jean-François (1995). L’espace public local et ses médiations. En: Hermès, $\mathrm{n}^{\mathrm{0}} 17-18,287-298$.

\section{Referencia de este artículo:}

Ballarini, Loïc (2012). ¿Por qué leer la prensa regional hoy en día? En: adComunica. Revista Científica de Estrategias, Tendencias e Innovación en Comunicación, $\mathrm{n}^{\circ}$ 4. Castellón: Asociación para el Desarrollo de la Comunicación adComunica, Universidad Complutense de Madrid y Universitat Jaume I, 99-117. DOI: http://dx.doi.org/10.6035/2174-0992.2012.4.7 